\title{
Risk score system for late aortic events in patients with uncomplicated type $B$ aortic dissection
}

\author{
Akihito Matsushita, MD, ${ }^{\mathrm{a}, \mathrm{b}}$ Minoru Tabata, MD, PhD, MPH, ${ }^{\mathrm{c}}$ Wahei Mihara, MD, ${ }^{\mathrm{a}}$ \\ Takeshi Shimamoto, MD, PhD, ${ }^{d}$ Tatsuhiko Komiya, MD, PhD, ${ }^{\mathrm{d}}$ Shuichiro Takanashi, MD, PhD, \\ Tetsuya Tobaru, MD, PhD, ${ }^{\mathrm{f}}$ Tatsuya Nakao, MD, PhD, ${ }^{\mathrm{g}}$ Sunao Nakamura, $\mathrm{MD}, \mathrm{PhD},{ }^{\mathrm{h}}$ and \\ Yasunori Sato, $\mathrm{PhD}^{\mathrm{i}}$
}

\section{ABSTRACT}

Objective: Several risk factors for late aortic events in patients with uncomplicated type B aortic dissection (UTBAD) have been reported; however, they remain controversial. We developed and validated a new risk prediction score system for late aortic events in patients with UTBAD.

Methods: We reviewed 187 consecutive patients diagnosed with UTBAD from 2004 to 2017 at 2 centers (derivation cohort) and 219 consecutive patients diagnosed with UTBAD from 2012 to 2016 in 4 other centers (validation cohort). We explored predictors of late aortic events using Fine-Gray generalization of the proportional hazards model, then developed a risk prediction score model and determined the test reliability using time-dependent receiver operating characteristic analyses. Finally, we validated the model using external multicenter data.

Results: The risk prediction score system was developed using the following independent predictors: initial aortic diameter of $\geq 40 \mathrm{~mm}$ ( 2 points), false lumen diameter larger than true lumen diameter ( 2 points), ulcer-like projection (1 point), and age $\geq 70$ years ( 1 point). Receiver operating characteristic analysis showed that a cut-off total additive score of 2 points. In the validation cohort, the low-risk group (score, 0-1 point) demonstrated lower 1- and 3-year incidence rates of late aortic events than the high-risk group (score, $2-6$ points) $(0.9 \%$ vs $32.5 \%$ and $0.9 \%$ vs $47.1 \%$, respectively; $P<.0001$ ).

Conclusions: We developed a simple risk prediction score system for late aortic events in patients with UTBAD. High-risk patients can be identified using our model, and they should be closely monitored and considered for interventions at the appropriate timing. (J Thorac Cardiovasc Surg 2020;159:2173-83)

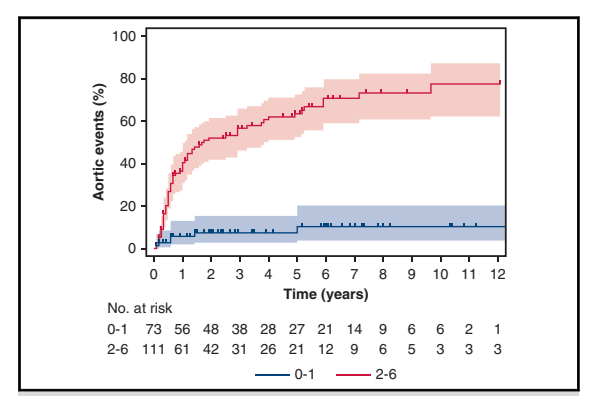

The cumulative incidence rates of late aortic events in the score derivation cohort.

\section{Central Message}

We developed and validated a simple risk prediction score system for late aortic events in patients with uncomplicated type B aortic dissection.

\section{Perspective}

Our risk prediction score system detected high-risk patients with uncomplicated type B aortic dissection as follows: patients with an initial aortic diameter $\geq 40 \mathrm{~mm}$ or patients with a false lumen diameter larger than true lumen diameter at admission or patients aged $\geq 70$ years with ulcer-like projections. These patients should be closely monitored and considered for interventions at the appropriate timing.

See Commentaries on pages 2184, 2185, and 2187.
Late aortic events in patients with uncomplicated acute Stanford type B aortic dissection (UTBAD) have poor outcomes. ${ }^{1}$ About $25 \%$ to $50 \%$ of patients who survive

\footnotetext{
From the ${ }^{a}$ Department of Cardiovascular Surgery, Seikeikai Chiba Medical Center, Chiba, Japan; 'bepartment of Global Clinical Research, Graduate School of Medicine, Chiba University, Chiba, Japan; ${ }^{\mathrm{c} D e p a r t m e n t ~ o f ~ C a r d i o v a s c u l a r ~ S u r g e r y, ~}$ Tokyo Bay Urayasu Ichikawa Medical Center, Chiba, Japan; ${ }^{\mathrm{d}}$ Department of Cardiovascular Surgery, Kurashiki Central Hospital, Okayama, Japan; Departments of ${ }^{\mathrm{e}}$ Cardiovascular Surgery and ${ }^{\mathrm{f}}$ Cardiology, Sakakibara Heart Institute, Tokyo, Japan; Departments of ${ }^{\mathrm{g}}$ Cardiovascular Surgery and ${ }^{\mathrm{h}}$ Cardiology, New Tokyo Hospital, Chiba, Japan; and ${ }^{\mathrm{i}}$ Department of Preventive Medicine and Public Health, School of Medicine, Keio University, Tokyo, Japan.

Received for publication Dec 23, 2018; revisions received June 6, 2019; accepted for publication June 14, 2019; available ahead of print July 26, 2019.
}

the acute phase require open or endovascular aortic surgery for the dissected aorta during the chronic phase., ${ }^{2,3}$ Many reports have described thoracic endovascular aortic repair

\footnotetext{
Address for reprints: Akihito Matsushita, MD, Department of Cardiovascular Surgery, Seikeikai Chiba Medical Center, and Department of Global Clinical Research, Graduate School of Medicine, Chiba University, 1-7-1 Minami-cho, Chuo-ku, Chiba 260-0842, Japan (E-mail: matsushita@seikeikai-cmc.jp). 0022-5223

Copyright (C) 2019 by The American Association for Thoracic Surgery. Published by Elsevier Inc. This is an open access article under the CC BY-NC-ND license (http:// creativecommons.org/licenses/by-nc-nd/4.0/).

https://doi.org/10.1016/j.jtcvs.2019.06.019
} 


\section{Abbreviations and Acronyms}

UTBAD $=$ uncomplicated type $\mathrm{B}$ aortic dissection

TEVAR $=$ thoracic endovascular aortic repair

BMT = best medical treatment

$\mathrm{CT}=$ computed tomography

$\mathrm{ULP}=$ ulcer-like projection

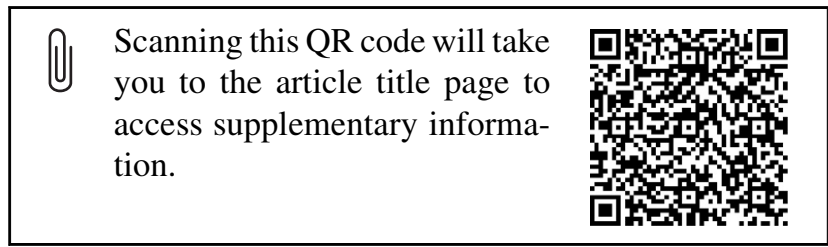

(TEVAR) for patients with UTBAD during the chronic phase; however, the indication and timing have not been well established. ${ }^{4,5}$ Two randomized trials compared the outcomes between best medical treatment (BMT) and BMT with TEVAR in patients with UTBAD. The Acute Dissection: Stent graft or Best medical Therapy (ADSORB) trial randomized 61 patients with UTBAD and indicated that additional TEVAR during the acute phase of disease is superior to medical therapy alone in terms of thrombosis of the false lumen in patients with
UTBAD; however, it showed no benefit of TEVAR in terms of mortality, prevention of aortic rupture, or dilatation. ${ }^{2}$ The Endovascular Repair of Type B Aortic Dissection-Long-term Results of the Randomized Investigation of Stent Grafts in Aortic Dissection (INSTEAD-XL) trial randomized 140 patients with UTBAD and revealed that the TEVAR group demonstrated a high thrombosis rate of the false lumen $(90.6 \%)$ and that the 5-year aortarelated mortality rate was lower in the TEVAR group than in the BMT-alone group $(6.9 \%$ vs $19.3 \%$, respectively; $P=.04) .{ }^{6}$ However, the 2-year aorta-related mortality rate was higher in the TEVAR group than in the BMTalone group $(6.9 \%$ vs $2.9 \%$, respectively). This unfavorable early outcome in the TEVAR group may have occurred because TEVAR was performed in all randomized patients with UTBAD without risk stratification. Patients at low risk of late aortic events might not receive clinical benefits of pre-emptive TEVAR. Which patients should undergo pre-emptive TEVAR remains controversial.

Many risk factors for late aortic events have been identified $^{7-15}$; however, a robust risk model predicting late aortic events after UTBAD has not been established. This study was performed to build a risk prediction score model for late aortic events in patients with UTBAD and validate it using large-size clinical data with a high follow-up rate.
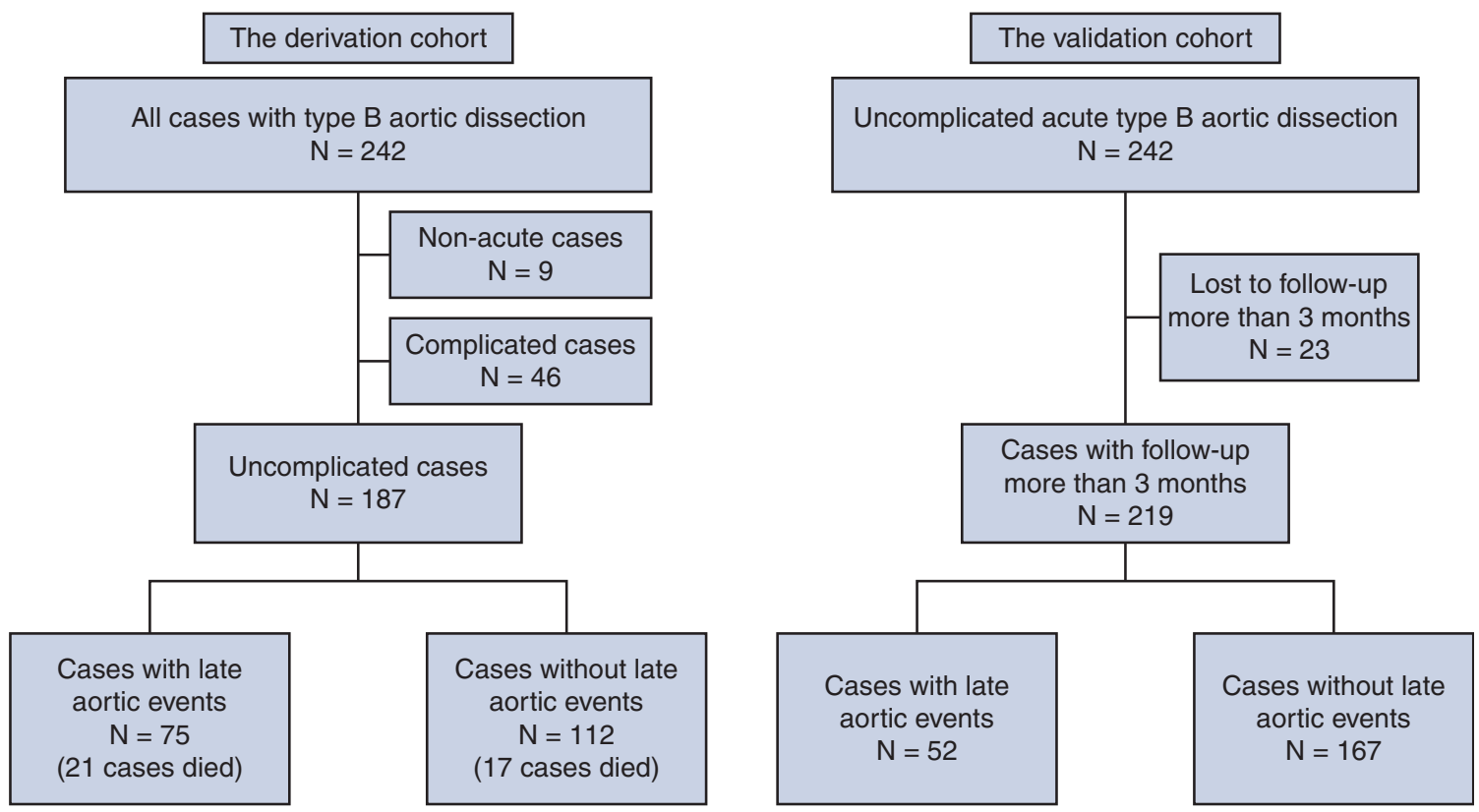

FIGURE 1. Flow diagram of the entire series of Stanford type B aortic dissection. The study comprised 187 patients in the derivation cohort and 219 patients in the validation cohort. We had 75 cases with late aortic events in the derivation cohort and 52 cases with late aortic events in the validation cohort. Late aortic events were defined as follows: late open surgery or thoracic endovascular aortic repair for the dissected aorta, rupture, or impending rupture, $\geq 55$ - $\mathrm{mm}$ dilatation of the dissected aorta, rapid dilatation of the dissected aorta ( $>5 \mathrm{~mm} / 6 \mathrm{mo}$ ), and saccular aneurysm. 
Zone 3: Distal aortic arch

Zone 4: Proximal descending aorta

T6: approximating the midpoint of the descending aorta

Zone 5: Distal descending aorta

Zone 6 to 7: Proximal abdominal aorta (Celiac artery level to renal artery level)

Zone 8 to 9: Distal abdominal aorta (Renal artery level to terminal aorta)
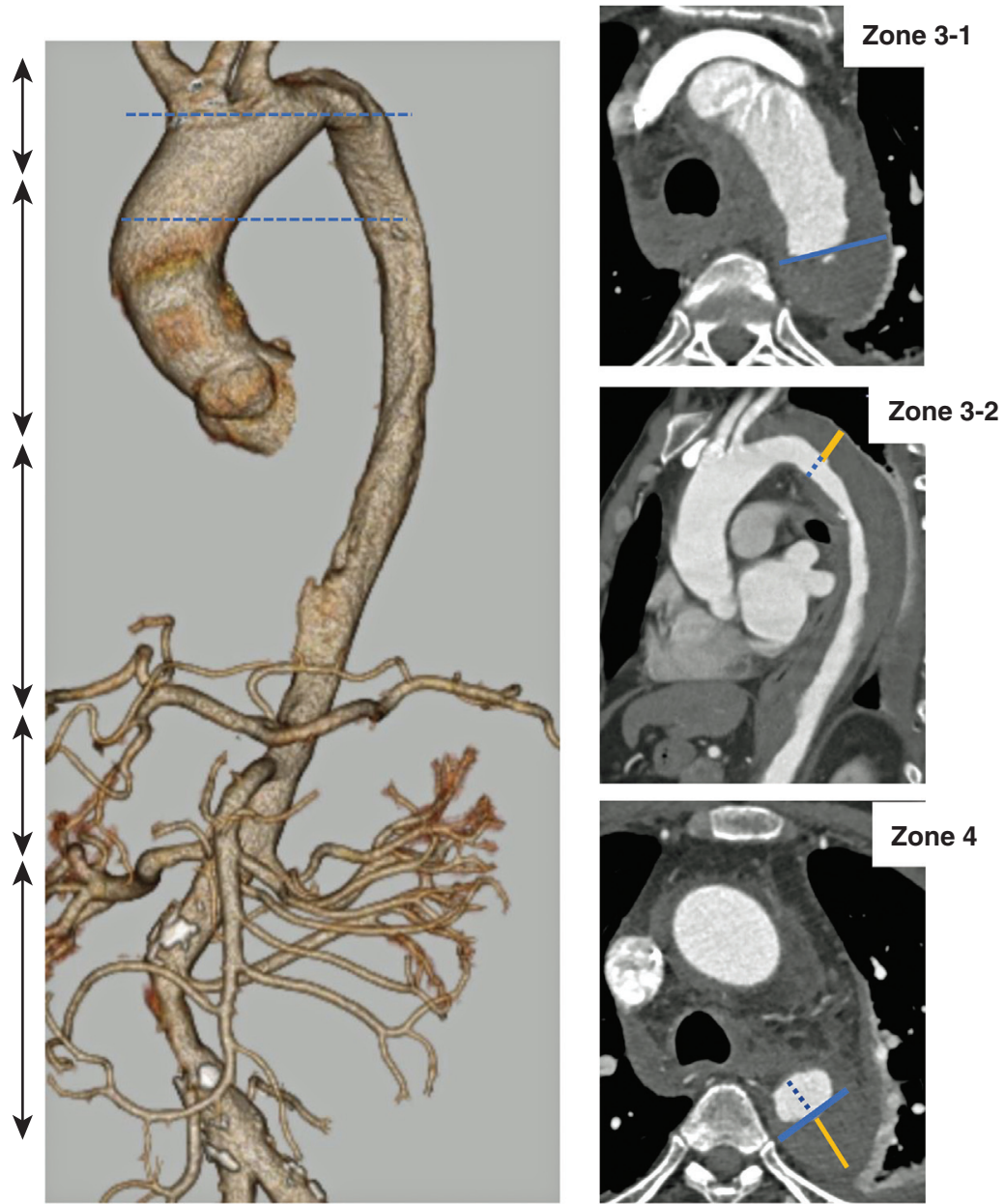

FIGURE 2. Computed tomography (CT) measurement technique. The diagnosis of aortic dissection was made with contrast-enhanced CT in all patients. We used the CT images at admission. We measured the aortic diameter and checked for false lumen patency on all CT images. The largest long-axis and short-axis diameters and false lumen thickness were measured at 5 sites according to a previously reported zone system: zone 3 (distal aortic arch), zone 4 (proximal descending aorta; T6 approximates the midpoint of the descending aorta), zone 5 (distal descending aorta), zone 6 to 7 (proximal abdominal aorta; celiac artery to renal artery), and zone 8 to 9 (distal abdominal aorta; infrarenal artery). Usually, we used the axial view for the short-axis diameter. We also used the sagittal view or coronal view for the false lumen thickness and long-axis diameter because evaluation of the long-axis cross-section of the aorta depends on the patient's bloodstream. The initial aortic diameter was defined as the largest short-axis diameter from any of the 5 sites.

\section{METHODS}

\section{Study Design and Setting}

We performed 2 retrospective cohort studies of a risk prediction score system for late aortic events in patients with UTBAD. The derivation cohort study enrolled 187 patients diagnosed with UTBAD from 2004 to 2017 in 2 centers (Chiba Central Medical Center, Chiba, Japan; and Seikeikai Chiba Medical Center, Chiba, Japan). The validation cohort study enrolled 219 patients diagnosed with UTBAD from 2012 to 2016 in 4 other centers (Kurashiki Central Hospital, Okayama, Japan; New Tokyo Hospital, Chiba, Japan; Sakakibara Heart Institute, Tokyo, Japan; and Tokyo Bay Urayasu Ichikawa Medical Center, Chiba, Japan) (Figure 1).

This study was approved by the Institutional Review Boards of Seikeikai Chiba Medical Center, Chiba University, Kurashiki Central Hospital; New Tokyo Hospital, Sakakibara Heart Institute, Tokyo Bay Urayasu Ichikawa Medical Center. A waiver of informed consent was obtained.

\section{Derivation Cohort Study}

From October 2004 to December 2017, 242 consecutive patients were diagnosed and treated for Stanford type B aortic dissection at Chiba Central Medical Center and Seikeikai Chiba Medical Center.

We excluded 9 patients with nonacute Stanford type B aortic dissection who had been diagnosed $\geq 2$ weeks after the onset of symptoms. We also excluded 46 patients with complicated type B aortic dissection (ie, rupture, impending rupture, and/or malperfusion). We retrospectively reviewed 187 consecutive patients with UTBAD. The final follow-up research, including telephone and letter interviews for some outpatients in other clinics, was conducted from January 2018 to May 2018. The median follow-up duration was 41 months (25th percentile [Quartile 1], 16 months and 75th percentile [Quartile 3], 72 months), the complete follow-up rate was $96.8 \%$, and 6 patients were lost to follow-up.

The diagnosis was made with contrast-enhanced computed tomography (CT) in all patents. Aortic dissection was classified according to the 
TABLE 1. Patient characteristics and computed tomography data early after onset in the derivation cohort

\begin{tabular}{|c|c|c|c|}
\hline Variables & $\begin{array}{l}\text { All patients } \\
(\mathbf{N}=187)\end{array}$ & $\begin{array}{l}\text { Late aortic events }(+) \\
\qquad(\mathbf{n}=75)\end{array}$ & $\begin{array}{l}\text { Late aortic events (-) } \\
\qquad(\mathrm{n}=112)\end{array}$ \\
\hline Age (y) & $66.9 \pm 12.1$ & $66.2 \pm 12.0$ & $67.3 \pm 12.2$ \\
\hline Male & $130(69.5)$ & $60(80.0)$ & $70(62.5)$ \\
\hline Hypertension & $185(98.9)$ & $75(100)$ & $110(98.2)$ \\
\hline Hyperlipidemia & $43(23.0)$ & $14(18.7)$ & $29(25.9)$ \\
\hline Diabetes mellitus & $17(9.1)$ & $7(9.3)$ & $10(8.9)$ \\
\hline Hemodialysis & $5(2.7)$ & $1(1.3)$ & $4(3.6)$ \\
\hline Peripheral artery disease & $12(6.4)$ & $7(9.3)$ & $5(4.5)$ \\
\hline Coronary artery disease & $26(13.9)$ & $10(13.3)$ & $16(14.3)$ \\
\hline Cerebral infarction & $14(7.5)$ & $7(9.3)$ & $7(6.3)$ \\
\hline Chronic obstructive pulmonary disease & $16(8.6)$ & $3(4.0)$ & 13 (11.6) \\
\hline \multicolumn{4}{|l|}{ De Bakey classification } \\
\hline Type IIIa* & $64(34.2)$ & $28(37.3)$ & $36(32.1)$ \\
\hline Type IIIb $\dagger$ & $123(65.8)$ & $47(62.7)$ & $76(67.9)$ \\
\hline Patent false lumen at admission & $100(53.5)$ & $40(53.3)$ & $60(53.6)$ \\
\hline Initial aortic diameter $\geq 40 \mathrm{~mm}$ & $73(39.0)$ & $51(68.0)$ & $22(19.6)$ \\
\hline False lumen diameter larger than true lumen diameter & $47(25.1)$ & $28(37.3)$ & $19(16.7)$ \\
\hline Ulcer-like projection & $38(20.3)$ & $22(29.3)$ & $16(14.3)$ \\
\hline Systolic blood pressure $\geq 120 \mathrm{~mm} \mathrm{Hg} 1$ y after onset & $103(55.1)$ & $48(64.0)$ & $55(49.1)$ \\
\hline
\end{tabular}

Values are presented as mean \pm standard deviation or $\mathrm{n}(\%)$. *Aortic dissection stops above the diaphragm. $\dagger$ Aortic dissection extends below the diaphragm.

Stanford classification as type $B$ if the dissection did not involve the ascending aorta. We included type B intramural hematoma in the study group because it was difficult to distinguish between intramural hematoma and aortic dissection with a totally thrombosed false lumen. ${ }^{16}$ We described our acute aortic dissection protocol in a past study. ${ }^{7}$ All cases of UTBAD were managed medically regardless of the false lumen status or the aortic diameter. Medical management included admission to the intensive care unit, continuous blood pressure monitoring, central venous access for intravenous antihypertensive medication, and urine output monitoring. We routinely followed-up the dissected aorta with contrastenhanced CT scans at 1 day, 7 days, and 2 weeks after admission unless a patient had renal dysfunction. Systolic blood pressure was controlled between 100 and $120 \mathrm{~mm} \mathrm{Hg}$. We also closely monitored patients after discharge and tried to maintain their systolic blood pressure $<120 \mathrm{~mm}$
$\mathrm{Hg}$; however, strict blood pressure control was not achieved in 103 patients $(55.1 \%)$ at 1 year after diagnosis. During follow-up, contrast-enhanced CT scans were performed at 3 to 6 months, 1 year, and annually thereafter.

\section{Validation Cohort Study}

The validation cohort comprised 242 consecutive patients who were diagnosed and treated for acute UTBAD at Kurashiki Central Hospital, New Tokyo Hospital, Sakakibara Heart Institute, and Tokyo Bay Urayasu Ichikawa Medical Center from January 2012 to December 2016. We excluded 23 patients who were not followed for $>3$ months. We retrospectively reviewed 219 consecutive patients with UTBAD. The median follow-up duration was 36 months (Quartile 1, 22 months and Quartile 3, 50 months).

Before analysis of the validation data, the scoring system was developed from the derivation set as described below. We calculated predictive scores

TABLE 2. Univariate and multivariate analyses for predictors of late aortic events in the derivation cohort

\begin{tabular}{|c|c|c|c|c|c|}
\hline \multirow[b]{2}{*}{ Predictors } & \multirow{2}{*}{$\frac{\text { Univariate }}{P \text { value }}$} & \multicolumn{3}{|c|}{ Multivariate } & \multirow[b]{2}{*}{ Score (points) } \\
\hline & & $\begin{array}{c}\text { Hazard ratio } \\
(95 \% \text { confidence interval })\end{array}$ & $P$ value & $\beta$ coefficient & \\
\hline Age $\geq 70$ y & .066 & $1.918(1.171-3.142)$ & .009 & 0.651 & 1 \\
\hline Male sex & .063 & $1.165(0.598-2.269)$ & .652 & & \\
\hline Patent false lumen & .653 & $0.692(0.396-1.210)$ & .197 & & \\
\hline Initial aortic diameter $\geq 40 \mathrm{~mm}$ & $<.001$ & $4.108(2.343-7.203)$ & $<.001$ & 1.412 & 2 \\
\hline False lumen diameter larger than true lumen diameter & .002 & $4.207(2.286-7.742)$ & $<.001$ & 1.436 & 2 \\
\hline Ulcer-like projection & .012 & $2.100(1.161-3.485)$ & .009 & 0.741 & 1 \\
\hline Systolic blood pressure $\geq 120 \mathrm{~mm} \mathrm{Hg} 1$ y after onset & .209 & $1.330(0.806-2.194)$ & .264 & & \\
\hline
\end{tabular}



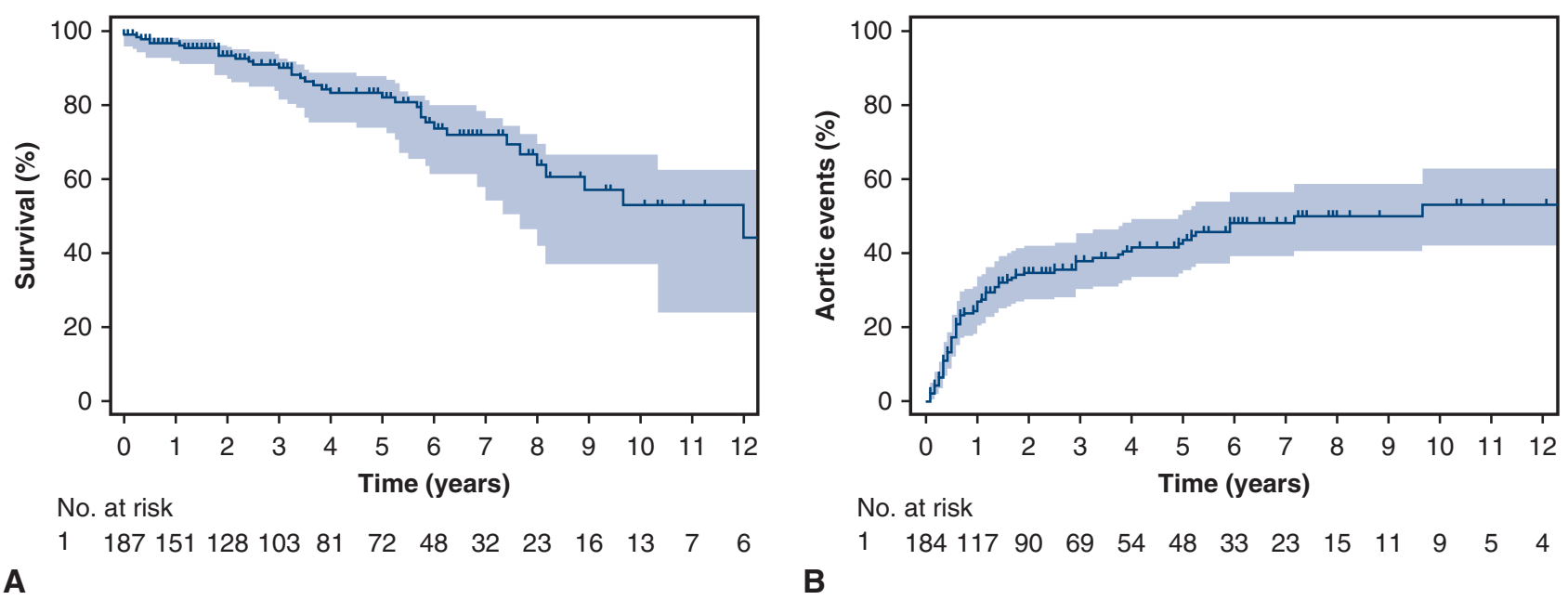

FIGURE 3. Cumulative incidence curves in the derivation cohort. A, Cumulative incidence of freedom from all-cause death having no relation to aortic events in the derivation cohort with the confidence limits as a colored shaded area. The actuarial survival rates were $96.3 \%$ at 1 year, $89.8 \%$ at 3 years, and $81.9 \%$ at 5 years. B, Cumulative incidence of late aortic events in the derivation cohort with the confidence limits as a colored shaded area. The cumulative incidence rates of late aortic events were $24.2 \%$ at 1 year, $38.1 \%$ at 3 years, and $44.5 \%$ at 5 years.

for each patient using clinical data obtained from the medical records; we also collected data on the presence and timing of late aortic events from the medical records.

\section{Data Collection and Definitions}

All clinical data were retrospectively collected from each patient's medical record during in-hospital or regular outpatient visits. UTBAD was defined as follows: the absence of malperfusion (any newly developed symptom with the presence of false lumen expansion that impaired true lumen flow on the CT images), no aortic rupture, and no continuous symptom despite optimal medical treatment with analgesic and/or antihypertension medication). In-hospital mortality was defined as any death before discharge.

We measured the aortic diameter and false lumen thickness and patency on all CT scan images. The largest long axis and short axis diameters and false lumen thickness were measured at 5 different portions according to the zone system described in our past study ${ }^{7}$ (Figure 2). The initial aortic diameter was defined as the largest short axis diameter of the dissected aorta on CT scan at admission. A patent false lumen was defined as any contrast effect in the false lumen during the early or late vascular phase, excluding ulcer-like projections (ULPs). A ULP was defined as a focal, well-defined pouch of contrast medium measuring $\leq 10 \mathrm{~mm}$ in length and projecting into the noncommunicating false lumen along the long axis of the aorta. The median age was 68 years (Quartile 1, 60 years and Quartile 3, 75 years) in the derivation cohort, and 70 years (Quartile 1, 61 years and Quartile 3, 78 years) in the validation cohort (Figure E1). We set age 70 years as the division point between younger patients and older patients.

Late aortic events were defined as follows: late open surgery or TEVAR for the dissected aorta after discharge from initial diagnosis and medical management, rupture, or impending rupture, $\geq 55-\mathrm{mm}$ dilatation of the dissected aorta, rapid dilatation of the dissected aorta $(>5 \mathrm{~mm} / 6 \mathrm{mo})$, and saccular aneurysm.

Aortic-related mortality was defined as death from aortic rupture, sudden unexplained death, or death from a newly developed acute Stanford type A aortic dissection.

\section{Statistical Analysis}

Summary statistics for the patient characteristics and CT scan data were constructed using frequency and proportion for categorical data and mean \pm standard deviation or median and 25th (Quartile 1) and 75th (Quartile 3) percentile, as appropriate, for continuous variables. Univariate analyses were carried out to test the association between potential predictors and late aortic events using the $t$ test or the Mann-Whitney $\mathrm{U}$ test for continuous variables and Fisher exact test for categorical variables. All potential predictors (Table 1) were entered into the univariate analyses; the variables with $P<.05$ and the major variables from previous literature

TABLE 3. Prediction score results and receiver operating characteristic analysis in the derivation phase

\begin{tabular}{|c|c|c|c|c|c|c|}
\hline Score & $\begin{array}{c}\text { Number of } \\
\text { patients }\end{array}$ & $\begin{array}{c}\text { Number of late } \\
\text { aortic events }\end{array}$ & $\begin{array}{c}\text { Sensitivity } \\
(\%)\end{array}$ & $\begin{array}{c}\text { Specificity } \\
(\%)\end{array}$ & $\begin{array}{c}\text { Positive predictive } \\
\text { value }(\%)\end{array}$ & $\begin{array}{c}\text { Negative predictive } \\
\text { value }(\%)\end{array}$ \\
\hline 0 & 36 & 1 & 100 & 0.0 & 40.1 & 0.0 \\
\hline 1 & 39 & 5 & 98.7 & 31.3 & 49.0 & 97.2 \\
\hline 2 & 41 & 19 & 92.0 & 61.6 & 61.6 & 92.0 \\
\hline 3 & 49 & 31 & 66.7 & 81.3 & 70.4 & 78.4 \\
\hline 4 & 16 & 14 & 25.3 & 97.3 & 86.4 & 66.1 \\
\hline 5 & 5 & 5 & 6.7 & 99.1 & 83.3 & 61.3 \\
\hline 6 & 1 & 0 & 0.0 & 99.1 & 0.0 & 59.7 \\
\hline
\end{tabular}




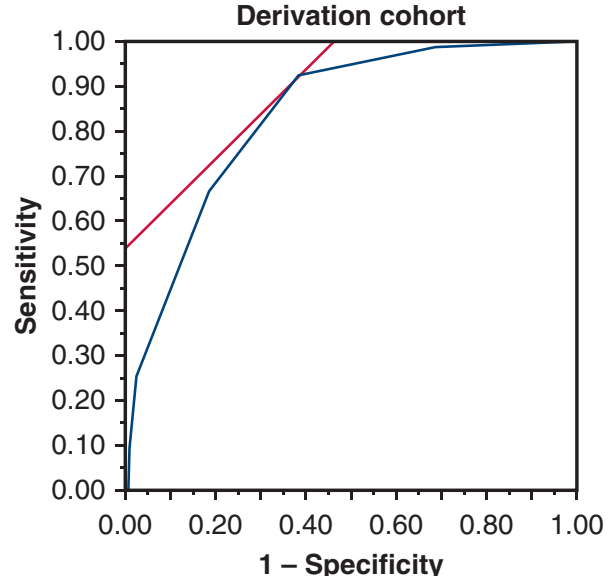

A

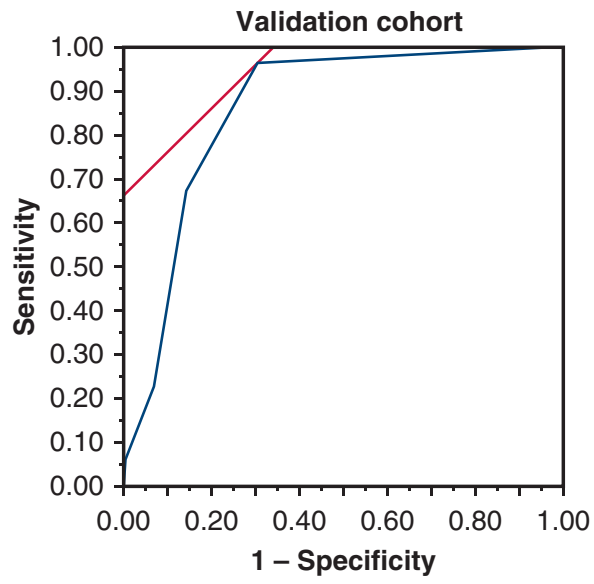

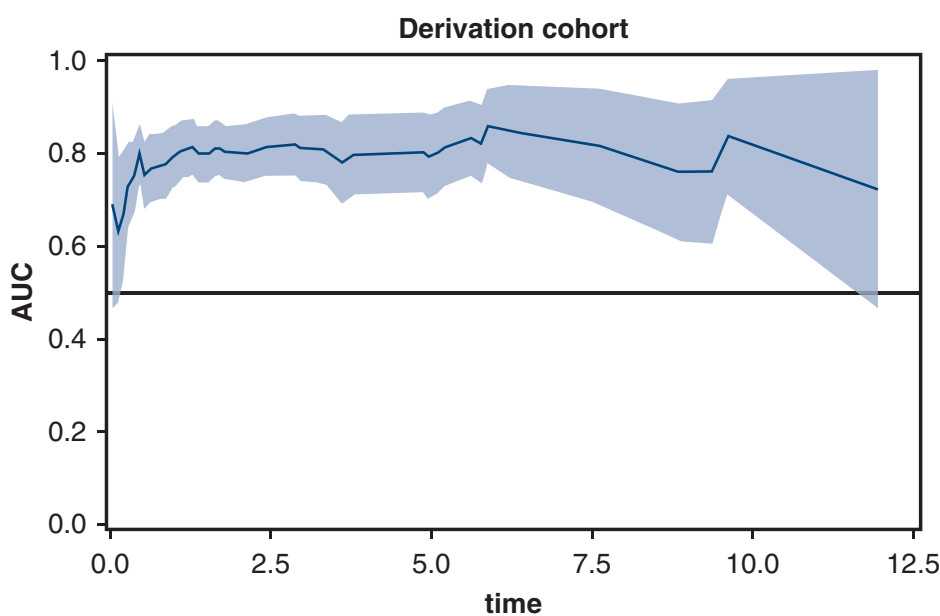

B

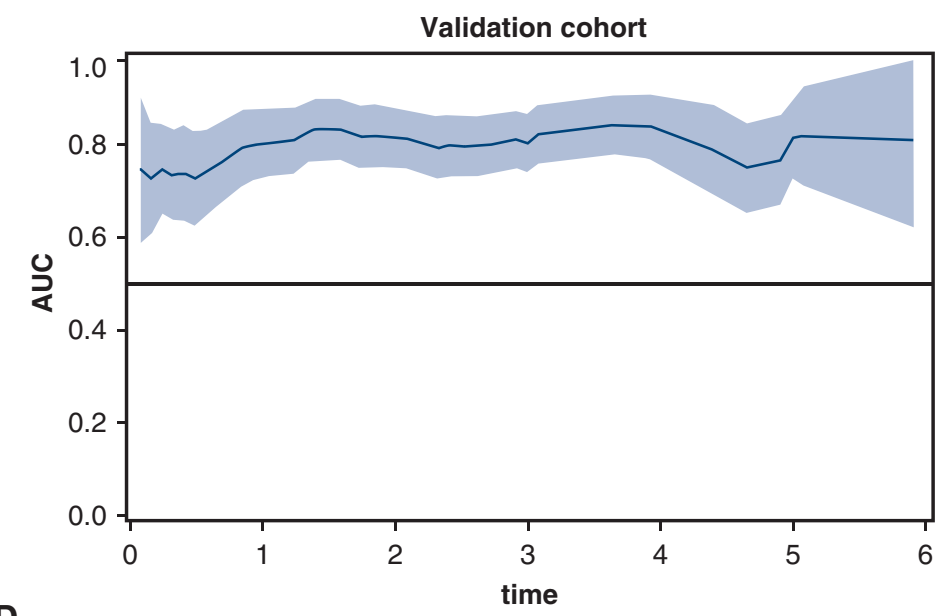

FIGURE 4. Receiver operating characteristic (ROC) curve analysis. The risk prediction score system for late aortic events was developed using the following independent predictors: initial aortic diameter $\geq 40 \mathrm{~mm}$ ( 2 points), false lumen diameter greater than true lumen diameter ( 2 points), ulcer-like projection ( 1 point), and age $\geq 70$ years ( 1 point). ROC curve analysis showed a cut-off score of 2 points in both the derivation cohort (Panel A) (area under the curve $[A U C], 0.83 ; P<.001)$ and the validation cohort (Panel C) (AUC, $0.85 ; P<.001$ ). We also revealed the time-related AUC by using the time related ROC analysis in both the derivation cohort (Panel B) and the validation cohort (Panel D) to assess the predictive accuracy of the risk score model.

were then selected for the multivariate model to detect the risk factors for late aortic events.

For time-to-late aortic event outcomes, the competing risk analysis was performed with the Fine-Gray generalization of the proportional hazards model accounting for death as a competing risk. The cumulative incidence curves were estimated by the Aalen-Johansen estimator. ${ }^{17}$ Death is a competing risk of loss to follow-up: patients who die can no longer become lost to follow-up. Competing risks are defined as events that prevent the outcome of interest from occurring.

To identify baseline and clinical variables associated with overall survival time, a multivariate analysis was performed using the Fine-Gray generalization of the proportional hazards model with the following covariates: age $\geq 70$ years, male sex, initial aortic diameter $\geq 40 \mathrm{~mm}$, patent false lumen, ULP, false lumen diameter larger than true lumen diameter, and systolic blood pressure of $\geq 120 \mathrm{~mm} \mathrm{Hg}$ during follow-up (Table 2). We selected these 7 covariates based on our clinical experience and previous literature to detect the risk factors for late aortic events. ${ }^{3,7-14}$
We constructed a simple predictive score system, including the significant variables from the Fine-Gray generalization of the proportional hazards model. The reference value was set from the average $\beta$ coefficients of 2 variables that were closest to 0 . The score was then assigned from the $\beta$ coefficient of each variable divided by the reference value (0.696). Time-dependent receiver operating characteristic (ROC) analysis was then applied to the risk scores.

All comparisons were planned, and the tests were 2-sided. All statistical analyses were initially performed using SAS version 9.4 (SAS Institute Inc, Cary, NC), SPSS version 22.0 (IBM-SPSS Inc, Armonk, NY), and $\mathrm{R}$ version 3.00 (R Foundation for Statistical Computing, Vienna, Austria).

\section{RESULTS}

\section{Derivation Cohort Study}

The patients' characteristics, initial admission data, and CT scan data are presented in Table 1 . The median duration 

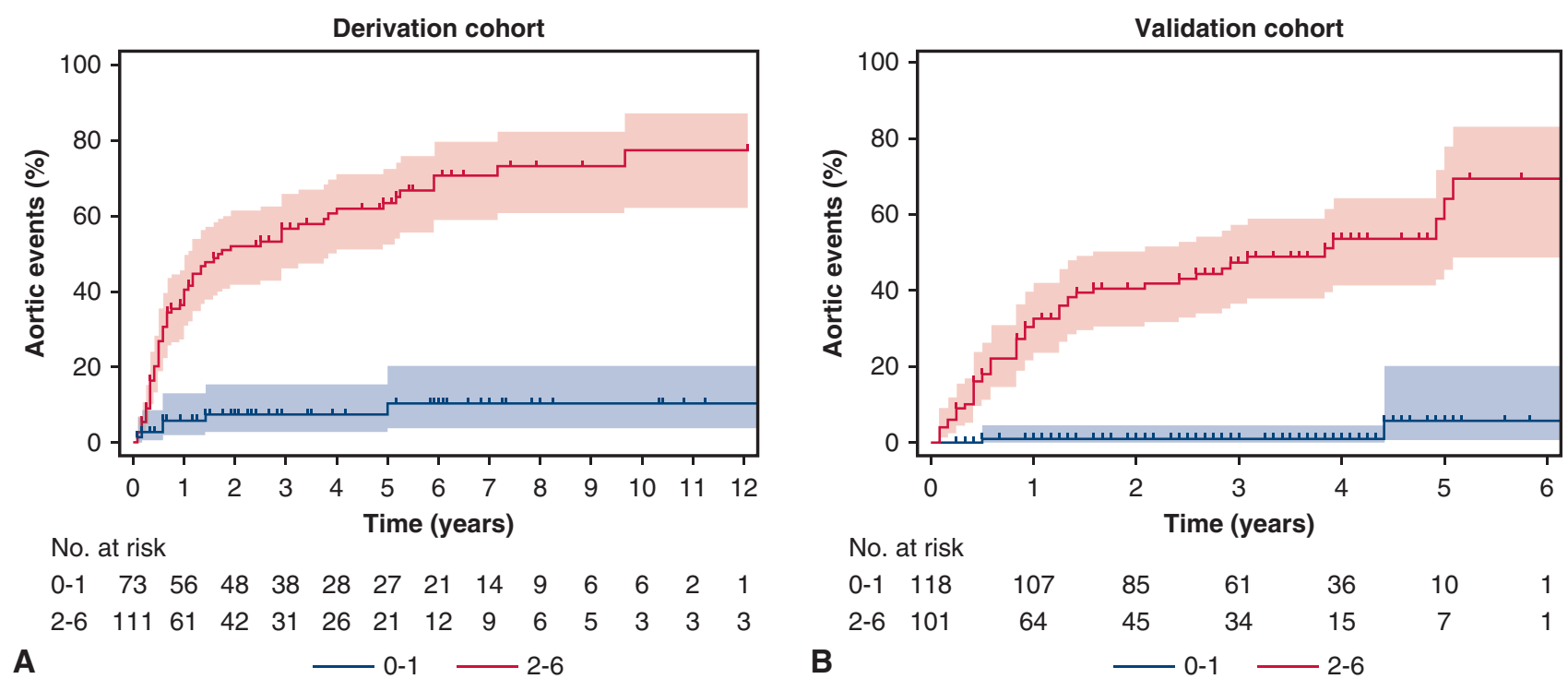

A $-0-1-2-6$

B

FIGURE 5. The cumulative incidence curves of late aortic events using the cumulative incidence method in each cohort. A, The cumulative incidence rates of late aortic events in patients with a prediction score of 0 to 1 and 2 to 6 points in the derivation cohort $(P<.0001)$. B, The cumulative incidence rates of late aortic events in patients with a prediction score of 0 to 1 and 2 to 6 points in the validation cohort $(P<.0001)$. We also revealed the confidence limits as a colored shaded area in the both figures. The high-risk group (score, 2-6 points) was consist of patients with initial aortic diameter $\geq 40 \mathrm{~mm}(2 \mathrm{points})$, false lumen diameter larger than true lumen diameter ( 2 points), ulcer-like projection ( 1 point) and age $\geq 70$ years ( 1 point).

of stay in the intensive care unit was 2 days (Quartile 1 days, 1 and Quartile 3, 3 days), and the median duration of hospitalization was 16 days (Quartile 1, 14 days and Quartile 3, 20 days). The in-hospital mortality rate was $0.5 \%(\mathrm{n}=1)$. One patient died of respiratory failure. During the follow-up, 37 patients $(19.9 \%)$ died. The cause of death was a late aortic event in 21 patients $(56.8 \%)$ and a nonaortic event in 16 patients $(43.2 \%)$. The actuarial survival rates were $96.3 \%$ at 1 year, $89.8 \%$ at 3 years, and $81.9 \%$ at 5 years (Figure $3, A$ ).

Seventy-five patients $(40.1 \%)$ developed late aortic events during the follow-up. An operation for the dissected aorta was performed in 49 patients $(26.2 \%)$. The reasons for the operation were $\geq 55$ - $\mathrm{mm}$ dilatation of the aorta in 22 patients, rapid dilatation of the aorta $(>10 \mathrm{~mm}$ per year) in 18 patients, dilatation of a ULP in 8 patients, and new development of an acute Stanford type A aortic dissection in 1 patient. Thirty-two patients underwent open aortic surgery: descending aorta replacement in 17 patients, total aortic arch replacement with the frozen elephant trunk technique in 6 patients, total aortic arch replacement without the frozen elephant trunk technique in 4 patients, staged descending aorta replacement in 3 patients, and abdominal aortic replacement in 2 patients. Seventeen patients underwent TEVAR for the dissected descending aorta.

During follow-up, 26 patients refused surgery despite having a $\geq 55$-mm dissected aorta or a saccular aneurysm; 10 died $(38.5 \%)$. The cumulative incidence rates of late aortic events were $24.2 \%$ at 1 year, $38.1 \%$ at 3 years, and $44.5 \%$ at 5 years (Figure 3, B).

\section{Risk Prediction Score System for Late Aortic Events in Patients With UTBAD}

From the Fine-Gray generalization of the proportional hazards model, the following 4 variables were identified as

TABLE 4. Patients' characteristics and computed tomography data early after onset in the validation cohort

\begin{tabular}{lccc}
\hline \multicolumn{1}{c}{ Variable } & All patients $(\mathbf{N}=\mathbf{2 1 9})$ & Late aortic events $(+)(\mathbf{n}=\mathbf{5 2})$ & Late aortic events $(-)(\mathbf{n}=\mathbf{1 6 7})$ \\
\hline Age $(\mathrm{y})$ & $68.0 \pm 13.5$ & $67.0 \pm 13.5$ & $68.3 \pm 13.5$ \\
Age $\geq 70 \mathrm{y}$ & $115(52.5)$ & $29(55.8)$ & $86(51.5)$ \\
Initial maximal minor axis aortic diameter $(\mathrm{mm})$ & $37.3 \pm 5.7$ & $42.8 \pm 6.0$ & $35.6 \pm 4.4$ \\
Initial aortic diameter $\geq 40 \mathrm{~mm}$ & $59(26.9)$ & $36(69.2)$ & $23(13.8)$ \\
False lumen diameter larger than true lumen diameter & $42(19.2)$ & $19(36.5)$ & $23(13.8)$ \\
Ulcer-like projection & $46(21.0)$ & $12(23.1)$ & $34(20.4)$ \\
\hline
\end{tabular}

Values are presented as mean \pm standard deviation or $\mathrm{n}(\%)$. 
TABLE 5. Prediction score results and receiver operating characteristic analysis in the validation phase

\begin{tabular}{lcccccc}
\hline Score & $\begin{array}{c}\text { Number of } \\
\text { patients }\end{array}$ & $\begin{array}{c}\text { Number of } \\
\text { late aortic events }\end{array}$ & $\begin{array}{c}\text { Sensitivity } \\
(\%)\end{array}$ & $\begin{array}{c}\text { Specificity } \\
(\%)\end{array}$ & $\begin{array}{c}\text { Positive predictive } \\
\text { value }(\%)\end{array}$ & $\begin{array}{c}\text { Negative predictive } \\
\text { value }(\%)\end{array}$ \\
\hline 0 & 44 & 1 & 100 & 0.0 & 23.7 & 0.0 \\
\hline 1 & 74 & 1 & 98.1 & 25.7 & 29.1 & 97.7 \\
\hline 2 & 42 & 15 & 96.2 & 69.5 & 49.5 & 98.3 \\
\hline 3 & 35 & 23 & 67.3 & 85.6 & 59.3 & 89.4 \\
\hline 4 & 20 & 9 & 23.1 & 92.8 & 50.0 & 79.5 \\
\hline 5 & 4 & 3 & 5.8 & 994 & 75.0 & 77.2 \\
\hline 6 & 0 & 0 & 0.0 & - & - & - \\
\hline
\end{tabular}

significant risk factors: initial aortic diameter of $\geq 40 \mathrm{~mm}$ (hazard ratio [HR], 4.11;95\% confidence interval [CI], 2.34-7.20; $P<.01)$, false lumen diameter larger than true lumen diameter (HR, 4.21; 95\% CI, 2.29-7.74; $P<.01)$, ULP (HR, 2.10; 95\% CI, 1.16-3.49; $P=.01$ ), and age $\geq 70$ years (HR, $1.92 ; 95 \% \mathrm{CI}, 1.17-3.14 ; P=.01)$. These 4 factors were incorporated into the risk prediction score using the integer point values from the $\beta$ coefficient and reference value of each variable as described above (Table 2). The scores ranged from 0 to 6 points. ROC analysis showed that a cut-off score of 2 points had a sensitivity of $92.0 \%$ and specificity of $61.6 \%$ (area under the curve, $0.83 ; P<.001)$. All ROC analysis results are shown in Table 3, and the ROC curve is shown in Figure 4, A. The low probability group (score, 0-1) demonstrated lower 1- and 3-year incidence rates of late aortic events than the high probability group (score, $2-6)(5.7 \%$ vs $40.8 \%$ and $7.4 \%$ vs $57.6 \%$, respectively; $P<.0001$ ) (Figure $5, A$ ).

\section{Validation Cohort Study}

The patients' characteristics and initial CT data are presented in Table 4. Late aortic events occurred in 52 patients $(23.7 \%)$. The median length to late aortic events was 10 months (Quartile 1, 5 months and Quartile 3, 16 months). A late operation for the dissected aorta was performed in 31 patients $(26.2 \%)$. During follow-up, 21 patients refused surgery despite having a $\geq 55-\mathrm{mm}$ dissected aorta or a saccular aneurysm.

Time-dependent ROC analysis showed that a cut-off score of 2 points had a sensitivity of $96.2 \%$ and specificity of $69.5 \%$ (area under the curve, $0.85 ; P<.001$ ). All ROC analysis results are shown in Table 5, and the ROC curve is shown in Figure 4, $C$. The low probability group (score, 0-1) demonstrated lower 1- and 3-year incidence rates of late aortic events than the high probability group (score, $2-6)(0.9 \%$ vs $32.5 \%$ and $0.9 \%$ vs $47.1 \%$, respectively; $P<.0001$ ) (Figure 5, B).

\section{Comparison of Derivation and Validation Sets}

The variables included in the scoring system were compared between the derivation and validation cohorts and are presented in Table 6. There were more patients with an initial aortic diameter $>40 \mathrm{~mm}$ and thereby more high-risk patients (score, 2-6) in the derivation than validation cohort $(59.9 \%$ vs $46.1 \%$, respectively; $P=.004)$. The cumulative incidence curves estimated that the 1- and 3-year aortic event incidence rates were $24.2 \%$ and $38.1 \%$, respectively, in the derivation cohort and were $15.6 \%$ and $22.9 \%$, respectively, in the validation cohort $(P=.510)$ (Figure 6). Although the differences between the cohorts were not statistically significant, the derivation cohort showed higher late aortic event rates

TABLE 6. Comparison of variables included in the scoring system between the derivation and validation cohorts

\begin{tabular}{|c|c|c|c|c|}
\hline Variable & $\begin{array}{l}\text { All patients } \\
(n=406)\end{array}$ & $\begin{array}{l}\text { Patients in the } \\
\text { derivation cohort }(n=187)\end{array}$ & $\begin{array}{l}\text { Patients in the } \\
\text { validation cohort }(n=219)\end{array}$ & $\begin{array}{c}P \\
\text { value }\end{array}$ \\
\hline Age $(y)$ & $67.5 \pm 12.9$ & $66.9 \pm 12.1$ & $68.0 \pm 13.5$ & .396 \\
\hline Age $\geq 70$ y & $200(49.3)$ & $85(45.5)$ & $115(52.5)$ & .164 \\
\hline Initial maximal minor axis aortic diameter (mm) & $37.8 \pm 6.2$ & $38.3 \pm 6.7$ & $37.3 \pm 5.7$ & .091 \\
\hline Initial aortic diameter $\geq 40 \mathrm{~mm}$ & $132(32.5)$ & $73(39.0)$ & $59(26.9)$ & .011 \\
\hline False lumen diameter larger than true lumen diameter & $89(21.9)$ & $47(25.1)$ & $42(19.2)$ & .151 \\
\hline Ulcer-like projection & $84(20.7)$ & $38(20.3)$ & $46(21.0)$ & .903 \\
\hline Number of patients with score $\geq 2$ & $213(52.5)$ & $112(59.9)$ & $101(46.1)$ & .004 \\
\hline Number of patients with late aortic events & $127(31.3)$ & $75(40.1)$ & $52(23.7)$ & $<.001$ \\
\hline
\end{tabular}

Data are presented as mean \pm standard deviation or $\mathrm{n}(\%)$. 


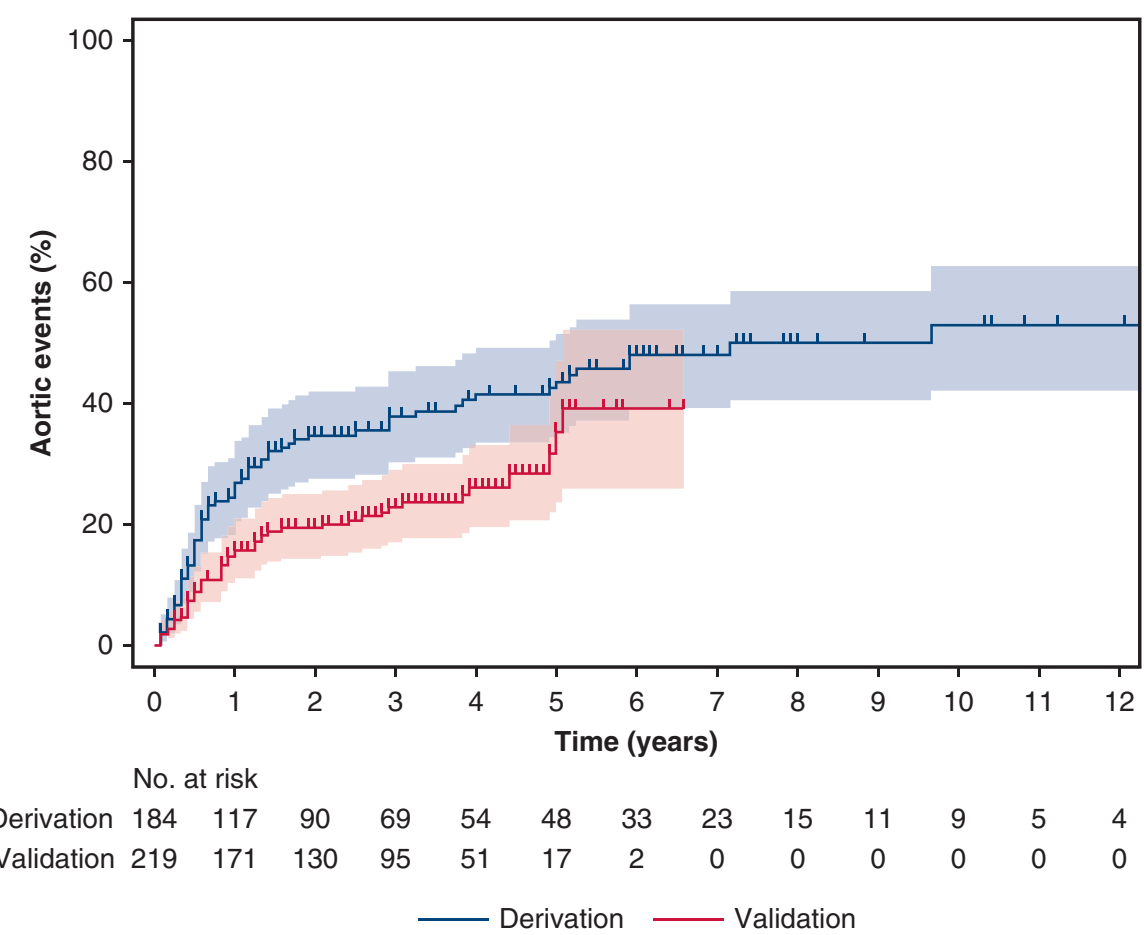

FIGURE 6. The late aortic events cumulative incidence curve in the both cohorts. There was not significantly difference of the late aortic events cumulative incidence rates between patients in the derivation cohort and patients in the validation cohort $(P=.510)$. We also reveal confidence limits as a shaded area.

than the validation cohort, which was compatible with the different patient profiles in the 2 cohorts.

\section{DISCUSSION}

Several studies have identified certain clinical factors, laboratory findings, and imaging findings as predictors of late aortic events after UTBAD that can be used to define high-risk UTBAD. ${ }^{7-15}$ However, all of these studies used a relatively small sample from a single center, and none of them validated their risk factors. Moreover, previous studies selected too many risk factors and suggested a relatively complex risk prediction method. Therefore, we developed a simple risk prediction score system for late aortic events in patients with UTBAD and validated it using multicenter data. Our study included 187 patients in the derivation cohort and 219 patients in the validation cohort, which is a larger sample size than in any previous studies. We identified 4 risk factors from the multivariate analysis of our derivation cohort data (initial aortic diameter of $\geq 40 \mathrm{~mm}$, false lumen diameter larger than true lumen diameter, ULP, and age $\geq 70$ years) and built a simple additive risk score system. These variables are very easy to collect and the risk score is very easy to calculate.

The cut-off total additive risk score was 2 points. The finding of an initial aortic diameter $\geq 40 \mathrm{~mm}$ or false lumen diameter larger than true lumen diameter automatically indicates a high risk for late aortic events regardless of the patient's age and presence of ULP. Many studies have suggested imaging factors as the major predictors of late aortic events. Patients with a large aorta from the beginning and/or a rapidly expanding aorta may have a high risk of late aortic events. The initial aortic diameter has been identified as among the most important predictors of late aortic events, and the cut-off initial aortic diameter was $40 \mathrm{~mm}$ in our previous $\operatorname{study}^{7}$ and in most previous studies (Figure E2) ${ }^{8,14}$ Tsai and colleagues ${ }^{15}$ suggested that the connection between the true lumen and false lumen influences the false lumen flow volume and flow blood pressure and influences the aortic diameter expansion during the follow-up period. The aortic growth rate is not linear; it is faster during the early phase than during the late phase, and a faster aortic growth rate is associated with increased aortic events. ${ }^{18}$ The various relationships between the true lumen and the false lumen have also been reported as predictors of late aortic events. Factors in these relationships include the size of the intimal tear, ${ }^{8}$ number of intimal tears ${ }^{9}$ or position of intimal tears, ${ }^{10}$ false lumen thickness, ${ }^{11}$ elliptical configuration of the true lumen, ${ }^{10}$ patent false lumen, ${ }^{12}$ partially thrombosed false lumen, ${ }^{13}$ position of the false lumen, ${ }^{10}$ and areas with localized dissection or ULP. ${ }^{12,14}$ In addition, Tolenaar and colleagues ${ }^{10}$ reported that the configuration of the false lumen reflects the pressure inside it and that an elliptical configuration of the true lumen in combination with a circular formation of the false lumen is associated with increased aortic growth. Some of these 
Simple risk prediction score system for late aortic events in patients with uncomplicated type B aortic dissection

Temporal change of the dissected aorta

Ulcer-like projection (1 point), and age of $\geq 70$ years ( 1 point)
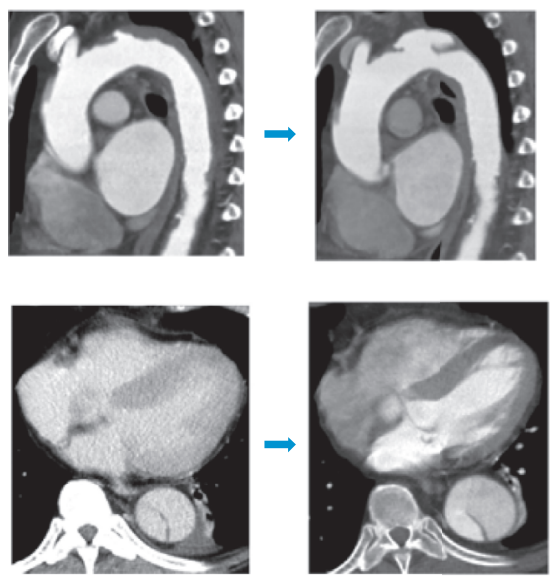

False lumen $>$ True lumen (2 points)

Initial aortic diameter of $\geq 40 \mathrm{~mm}$ (2 points)

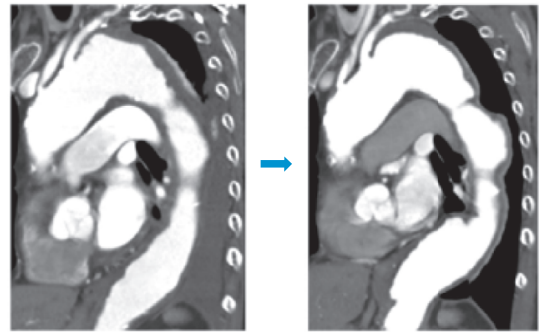

The patients with total additive score of 2-6 points were high-risk group of late aortic events.

\section{The late aortic events cumulative incidence curve} in the multicenter validation cohort.

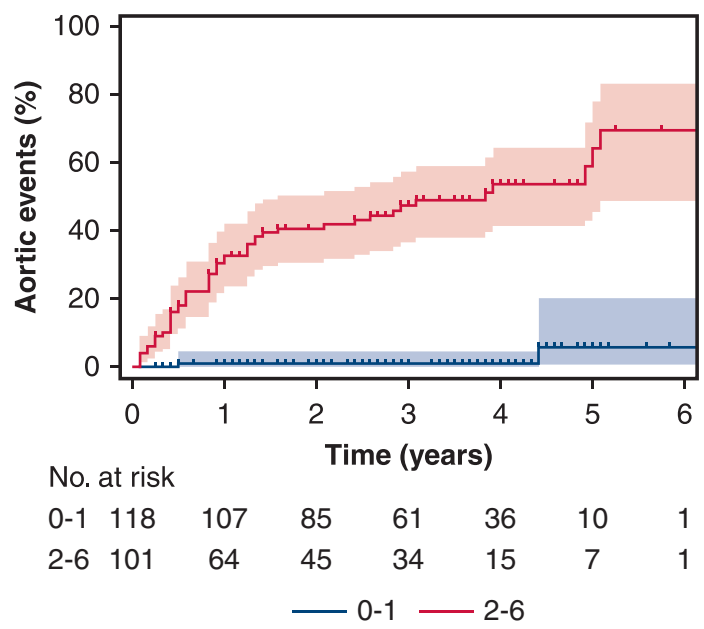

FIGURE 7. Risk score system for late aortic evens in patients with uncomplicated type B aortic dissection. The risk prediction score system was developed using the following independent predictors: initial aortic diameter $\geq 40 \mathrm{~mm}$ ( 2 points), false lumen diameter larger than true lumen diameter ( 2 points), ulcerlike projection ( 1 point), and age $\geq 70$ years ( 1 point). Receiver operating characteristic analysis showed a cut-off total additive score of 2 points. The patients with total additive score of 2 to 6 points were at high risk of late aortic events. In the validation cohort, the low-risk group (score, $0-1$ point) demonstrated lower 1- and 3-year incidence rates of late aortic events than the high-risk group (score, $2-6$ points) $(0.9 \%$ vs $32.5 \%$ and $0.9 \%$ vs $47.1 \%$, respectively; $P<.0001)$.

factors can be difficult to detect in some cases. ${ }^{19}$ However, the finding of a false lumen diameter larger than true lumen diameter is easy to detect on CT images in any case.

Even without 2 important imaging findings, older patients with UTBAD and ULP should be considered to be at high risk of experiencing late aortic events. However, some previous studies showed that younger patients were at higher risk of aortic events. ${ }^{10,14}$ This discrepancy could be explained by our inclusion of some patients with intramural hematoma, which is generally difficult to differentiate from aortic dissection with a completely thrombosed false lumen. Age $\geq 70$ years has been identified as a predictor of disease progression in patients with type $\mathrm{B}$ intramural hematoma. ${ }^{12}$ The same study showed that ULP was a risk factor for disease progression in patients with type B intramural hematoma. In addition, several studies have identified clinical predictors of late aortic events such as Marfan syndrome and white race. $^{3,8,20}$ No patients in our cohorts had Marfan syndrome, and no race diversity was present; this might have contributed to the discrepancy in the results among previous studies and our study. We found some differences in patient profiles between the derivation and validation sets. The proportion of patients with an initial aortic diameter $\geq 40 \mathrm{~mm}$ was significantly higher in the derivation than validation cohort $(39.0 \%$ vs $26.9 \%$, respectively; $P=.011)$. Thereafter, the proportion of high-risk patients (score, 2-6) was significantly higher in the derivation than validation cohort $(59.9 \%$ vs $46.1 \%$, respectively; $P=.004$ ). Because we included different hospitals in different regions in the validation cohort, it seems natural that some differences were present in the patients' aortic profiles between the cohorts. The variability in the measurement of CT findings could be a reason for the different patient profiles between the cohorts. Mendoza and colleagues $^{21}$ reported that the method by which the aortic diameter is measured on the axial CT slice results in a 3to $5-\mathrm{mm}$ difference in aortic diameter. They indicated that 
the aortic 3-dimensional view or double oblique slice is the most reliable way to measure the aortic diameter. ${ }^{21}$ Although we used the axial CT slice to measure aortic diameter, we believe that the variability in measurement in our study was minimal because we strictly defined the measurement method and our method was easy to perform.

\section{Limitations}

The present study has several limitations. In this study, we employed both type B aortic dissection with a thrombosed false lumen and type B intramural hematoma because these conditions were difficult to distinguish, as mentioned above. This is an important limitation because the natural evolution of intramural hematoma and aortic dissection are very different. This was an observational study performed at 2 centers during the derivation phase and at 4 centers during the validation phase in Japan, and the sample size and variables were limited. We lost 23 patients $(9.5 \%)$ to follow-up at $>3$ months in the validation cohort, and we excluded them from the analysis. This was not selective dropout, and the sample size was kept at the previous study level. A large prospective study and external validation studies in regions other than Japan are needed to determine the accuracy of this risk prediction score and further clarify the definition of high-risk UTBAD.

\section{CONCLUSIONS}

We developed a simple risk prediction score system for late aortic events in patients with UTBAD. The cut-off risk prediction score was set at 2 points, which revealed the following factors associated with a high risk of UTBAD: initial aortic diameter $\geq 40 \mathrm{~mm}$, false lumen diameter larger than true lumen diameter at admission, ULP, and age $\geq 70$ years (Figure 7). Moreover, the positive predictive value was higher when we combined these factors. We should closely monitor patients with these factors and consider intervention at the appropriate time.

\section{Conflict of Interest Statement}

Authors have nothing to disclose with regard to commercial support.

The authors thank Angela Morben, DVM, ELS, from Edanz Group (www.edanzediting.com/ac), for editing a draft of this manuscript.

\section{References}

1. Conway AM, Sadek M, Lugo J, Pillai JB, Pellet Y, Panagopoulos G, et al. Outcomes of open surgical repair for chronic type B aortic dissections. $J$ Vasc Surg. 2014;59:1217-23.

2. Hughes GC. Management of acute type B aortic dissection; ADSORB trial. J Thorac Cardiovasc Surg. 2015;149:S158-62.

3. Luebke T, Brunkwall J. Type B aortic dissection: a review of prognostic factors and meta-analysis of treatment options. Aorta. 2014;2:265-78.
4. Hiratzka LF, Bakris GL, Beckman JA, Bersin RM, Carr VF, Casey DE Jr, et al. 2010 ACCF/AHA/AATS/ACR/ASA/SCAI/SIR/STS/SVM guidelines for the diagnosis and management of patients with thoracic aortic disease: a report of the American College of Cardiology Foundation/American Heart Association Task Force on Practice Guidelines, American Association for Thoracic Surgery, American College of Radiology, American Stroke Association, Society of Cardiovascular Anesthesiologists, Society for Cardiovascular Angiography and Interventions, Society of Interventional Radiology, Society of Thoracic Surgeons, and Society for Vascular Medicine. Circulation. 2010;121:e266-369.

5. Erbel R, Aboyans V, Boileau C, Bossone E, Bartolomeo RD, Eggebrecht H, et al. 2014 ESC guidelines on the diagnosis and treatment of aortic diseases. Eur Heart J. 2014;35:2873-926.

6. Nienaber CA, Kische S, Rousseau H, Eggebrecht H, Rehders TC, Kundt G, et al. Endovascular repair of type B aortic dissection: long-term results of the randomized investigation of stent grafts in aortic dissection trial. Circ Cardiovasc Interv. 2013;6:407-16.

7. Matsushita A, Hattori T, Tsunoda Y, Sato Y, Mihara W. Impact of initial aortic diameter and false-lumen area ratio on Type B aortic dissection prognosis. Interact Cardiovasc Thorac Surg. 2018;26:176-82.

8. Evangelista A, Salas A, Ribera A, Ferreira-Gonzalez I, Cuellar H, Pineda V, et al. Long-term outcome of aortic dissection with patent false lumen, predictive role of entry tear size and location. Circulation. 2012;125:3133-41.

9. Tolenaar JL, van Keulen JW, Trimarchi S, Jonker FH, van Herwaarden JA, Verhagen HJ, et al. Number of entry tears is associated with aortic growth in type B dissections. Ann Thorac Surg. 2013;96:39-42.

10. Tolenaar JL, van Keulen JW, Jonker FH, van Herwaarden JA, Verhagen HJ Moll FL, et al. Morphologic predictors of aortic dilatation in type B dissections J Vasc Surg. 2013;58:1220-5.

11. Shimamoto T, Komiya T, Tsuneyoshi H. Fate of uncomplicated acute type B aortic dissection and impact of concurrent aortic dilatation on remote aortic events. J Thorac Cardiovasc Surg. August 182018 [Epub ahead of print].

12. Kaji S, Akasaka T, Katayama M, Yamamuro A, Yamabe K, Tamita K, et al Long-term prognosis of patients with type B aortic intramural hematoma Circulation. 2003;108:307-11.

13. Tsai TT, Evangelista A, Nienaber CA, Myrmel T, Meinhardt G, Cooper JV, et al. Partial thrombosis of the false lumen in patients with acute type B aortic dissection. N Engl J Med. 2007;357:349-59.

14. Miyahara S, Mukohara N, Fukuzumi M, Morimoto N, Murakami H, Nakagiri K, et al. Long-term follow-up of acute type B aortic dissection: ulcer-like projections in thrombosed false lumen play a role in late aortic events. $J$ Thorac Cardiovasc Surg. 2011;142:e25-31.

15. Tsai TT, Schlicht MS, Khanafer K, Bull JL, Valassis DT, Williams DM, et al. Tear size and location impacts false lumen pressure in an ex vivo model of chronic type B aortic dissection. J Vasc Surg. 2008;47:844-51.

16. Uchida K, Imoto K, Karube N, Minami T, Cho T, Goda M, et al. Intramural hematoma should be referred to as thrombosed-type aortic dissection. Eur J Cardiothorac Surg. 2013;44:366-9.

17. Gooley TA, Leisenring W, Crowley J, Storer BE. Estimation of failure probabilities in the presence of competing risks: new representations of old estimators. Stat Med. 1999;18:695-706.

18. Hosn MA, Goffredo P, Zavala J, Sharp WJ, Katragunta N, Kresowik T, et al Analysis of aortic growth rates in uncomplicated type B aortic dissection. Ann Vasc Surg. 2018;48:133-40.

19. Genten MK, Weber TF, von Tengg-Kobligk H, Bockler D, Stiller W, Geisbusch P et al. Motion characterization of aortic wall and intimal flap by ECG-gated CT in patients with chronic B-dissection. Eur J Radiol. 2009;72:146-53.

20. Jonker FH, Trimarchi S, Rampoldi V, Patel HJ, O'Gara P, Peterson MD, et al. Aortic expansion after acute type B aortic dissection. Ann Thorac Surg. 2012; 94:1223-9.

21. Mendoza DD, Kochar M, Devereux RB, Basson CT, Min JK, Holmes K, et al Impact of image analysis methodology on diagnostic and surgical classification on patients with thoracic aortic aneurysms. Ann Thorac Surg. 2011;92:904-12

Key Words: uncomplicated, acute type B aortic dissection, aortic events, predictors 
The histogram of age

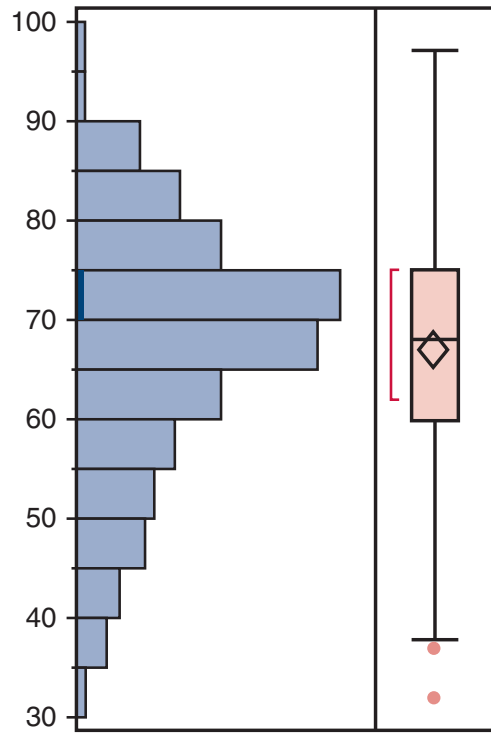

A The median age was 68 years old (Q1:60, Q3:75) in the derivation cohort.

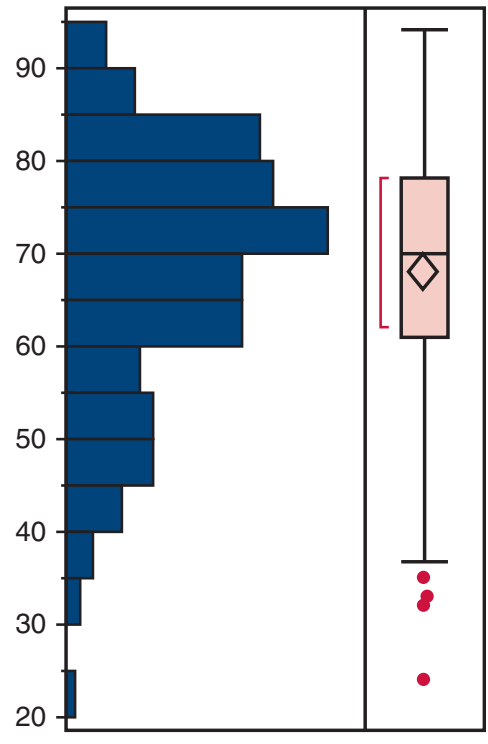

B The median age was 70 years old (Q1:61, Q3:78) in the validation cohort.

FIGURE E1. The histogram of age. A, Derivation cohort. B, Validation cohort.
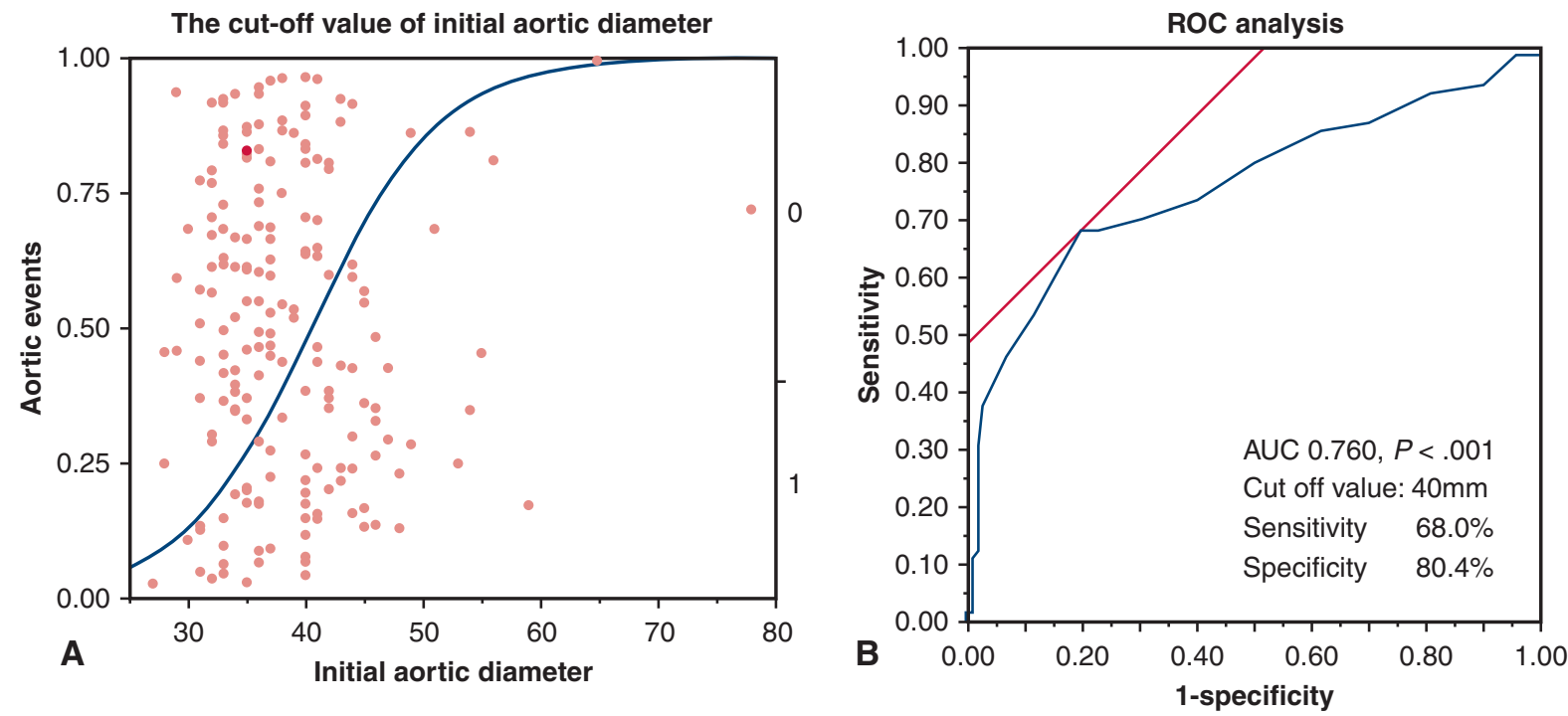

FIGURE E2. A, The cut-off value of initial aortic diameter. B, Receiver operator characteristic $(R O C)$ curve analysis. AUC, Area under the curve. 